\title{
Heerfordt's Syndrome: A New Atypical Clinical Presentation
}

\author{
Aitel-kerdoudi M*, Chafiki Z, Lakhdim M, Merzouki B, Rouadi S, Abada R, Roubal M and Mahtar M \\ Ibn Rochd University Hospital, Morocco
}

Submission: December 01, 2016; Published: March 27, 2017

*Corresponding author: Aitel-kerdoudi Mehdi, Hopital 20 Aout, ENT Service, CHU Ibn Rushd, Casablanca, Morocco,

Email : Mehdi.Kerdoudi@hotmail.com

\begin{abstract}
Heerfordt's syndrome is an unusual clinical manifestation (less than 5\%) of sarcoidosis, characterized by parotitis, uveitis, and peripheral facial palsy, febrile syndrome is usually associated. Oral corticosteroid is the treatment of choice. We report a case of a patient in which the syndrome of Heerfordt was retained.

Keywords: Heerfordt's syndrome, parotitis, uveitis, sarcoidosis, facial palsy.
\end{abstract}

\section{Introduction}

The sarcoidosis is a systemic granulomatosis of unknown cause, characterized by its clinical polymorphism and a wide variety of its modes of presentation. The combination of fever, uveitis, parotitis and peripheral facial paralysis defines Heerfordt's syndrome which presents an unusual manifestation of this disease. We report a case of a patient in which the syndrome of Heerfordt was found.

\section{Case Report}

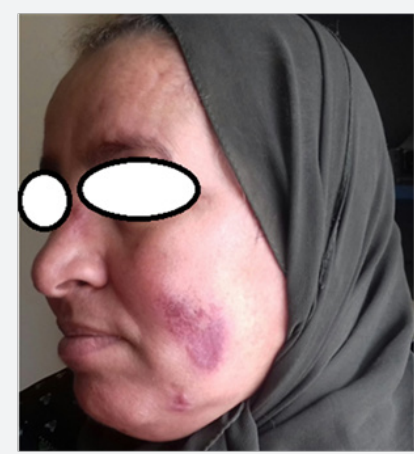

Figure 1: Erythema nodosum of the face.

A 49 year-old female followed in ophthalmology for bilateral uveitis, was referred to the ENT consultation for nasal obstruction with crusting rhinitis. General examination was unremarkableexcept a low-grade febrile state, especially there was no facial palsy. The patient has undergone a rhinocavoscopy which revealed the presence of nodular lesions in the lower horn. A biopsy of the lesions was performed which results normal. The evolution of the symptomatology was marked by the appearance of erythema nodosum on the face and the upper limbs (Figure 1).

The diagnosis of sarcoidosis was confirmed by the biopsy of the cutaneous lesions which showed non-caseatingepithelioid granulomas.

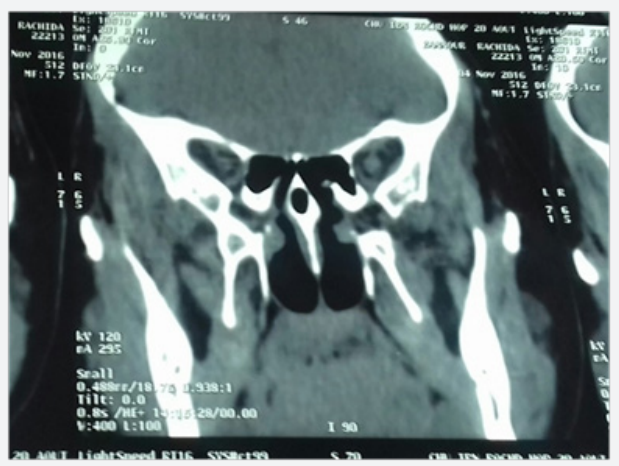

Figure 2: Facial CT scan - frontal section- bilateral parotid enlargement.

Facial CT scan highlighted a multinodular bilateral chronic parotitis (Figure 2), therefore, the diagnosis of Heerfordt's syndrome was retained in view of these highly evocative criteria even if the symptomatology was incomplete given the absence 
of facial palsy. The patient was initiated on long-term steroid therapy. After a month of treatment with oral steroids, clinical symptoms have shown a clear improvement.

\section{Discussion}

Sarcoidosis is a chronic inflammatory disorder of unknown etiology, characterized by noncaseating granulomas involving the lungs in more than $90 \%$ of patients. Ocular, lymph-node, and cutaneous manifestations are next in frequency, but any organ system can be affected by the disease.The diagnosis requires exclusion of other etiologies, such as Sjögren's syndrome, tuberculosis, fungal and parasitic infections, Wegener's granulomatosis [1].

Otolaryngologic manifestations are identified in 10-15 $\%$ of patients, the most common being cervical adenopathy [2]. Salivary glands are less frequently involved, unilateral or bilateral swelling of the parotid gland was reported in only $6-8 \%$ of patients with sarcoidosis [3]. It can be included in Heerfordt's syndrome (uveoparotid fever).

Heerfordt'ssyndrome is a sarcoidosissyndrome characterized by mild fever, painless parotid gland enlargement, cranial nerve involvement, and anterior uveitis [2]. It is considered as one of the first central nervous system involvements to be described as a neurological presentation of sarcoidosis. The complete form occurs in approximately $0.3 \%$ of all sarcoidosis cases [4]. The etiology of this condition is still unclear and, as a result, so is the pathogenesis [1].

The incidence of cranial nerve palsy in sarcoidosis is about $5 \%$ [5], with the facial nerve followed by the optic and the trigeminal nerves being the most common nerves involved [6]. Facial palsy forms an important defining component of Heerfordt's syndrome. Its approximate incidence in this syndrome is $25-50 \%$. However, its lack doesn't t eliminate the diagnosis as we have noticed in our case, in which the diagnosis of Heerfordt's syndrome was made based on the association of other highly suggestive criteria such as uveitis and parotitis.

The combination of both uveitis with blurred vision and facial nerve palsy could be performed as sarcoidosis [7]. As it is obviously noted in the literature that eye involvement was the most consistent finding in patients presenting with Heerfordt's syndrome, along with unilateral or bilateral facial palsy or parotid gland swelling [1]. Glucocorticosteroids remain the firstline therapy of Heerfordt's syndrome [1].

This case emphasizes the importance of recognizing the main signs and clinical symptoms which may be quite modest to indicate the diagnosis of this syndrome.

\section{Conclusion}

Head and neck manifestations of Heerfordt's syndrome are non-specific and a high suspicion is required to diagnose the condition early. In our case, Heerfordt's syndrome was retained before the association of parotitis and uveitis confirmed subsequently by the histological examination. The presence of peripheral facial paralysis is not necessary to make the diagnosis and must not delay its management.

\section{References}

1. Chappity P, Kumar R, Anjan K (2015) Sahoo Heerfordt's Syndrome Presenting with Recurrent Facial Nerve Palsy Case report and 10-year literature review. Sultan Qaboos Univ Med J 15(1): e124-128.

2. Badhey AK, Kadakia S, Carrau RL, Iacob C, Khorsandi A (2015) Sarcoidosis of the Head and Neck. Head Neck Pathol 9(2): 260-268.

3. Tabak L, Agirbas E, Yilmazbayhan D, Tanyeri H, Guc U (2001) The value of labial biopsy in the differentiation of sarcoidosis from tuberculosis. Sarcoidosis Vasc Diffuse Lung Dis 18(2): 191-195.

4. Sugawara Y, Sakayama K, Sada E, Kajihara M, Semba T, et al. (2005) Heerfordt syndrome initially presenting with subcutaneous mass lesions: Usefulness of gallium-67 scans before and after treatment. Clin Nucl Med 30(11): 732-733.

5. Burns TM (2003) Neurosarcoidosis. Arch Neurol 60(8): 1166-1168.

6. Christoforidis GA, Spickler EM, Recio MV, Mehta BM (1999) MR of CNS sarcoidosis: Correlation of imaging features to clinical symptoms and response to treatment. AJNR Am J Neuroradiol 20(4): 655-669.

7. Boucher RM, Grace J, Java DJ (1994) Sarcoidosis presenting as multiple cranial neuropathies and a parotid mass. Otolaryngol Head Neck Surg 111(5): 652-655.
This work is licensed under Creative

Commons Attribution 4.0 License

DOI: $10.19080 / J A I C M .2017 .02 .555576$

\section{Your next submission with Juniper Publishers} will reach you the below assets

- Quality Editorial service

- Swift Peer Review

- Reprints availability

- E-prints Service

- Manuscript Podcast for convenient understanding

- Global attainment for your research

- Manuscript accessibility in different formats

( Pdf, E-pub, Full Text, Audio)

- Unceasing customer service

Track the below URL for one-step submission https://juniperpublishers.com/online-submission.php 